\title{
Erratum
}

\section{A New Isocyanide Functionalization}

E. Alwedi, J. A. Lujan-Montelongo, B. R. Pitta, A. Chao, R. Cortés-Mejía, J. M. D. Campo, F. F. Fleming* Synfacts 2018, $14,1290$.

The scheme with the isonitrile-nitrile rearrangement contains a mistake.

The following scheme is correct:

Isonitrile-nitrile rearrangement:

Standard procedure

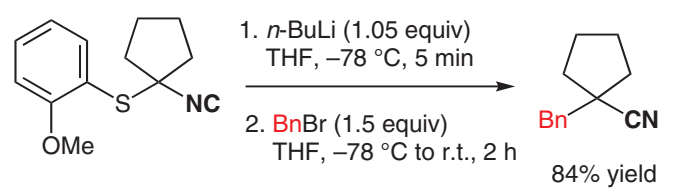

